Munk-Jorgenson, P. \& Mortensen, P. B. (1992) Incidence and other aspects of the epidemiology of schizophrenia in Denmark, 1971-87. British Journal of Psychiatry, 161, 489-495.

A.S. BROWN

J. BIRTWHISTLE

University of Southampton

Royal South Hants Hospital

Southampton SO14 OYG

\section{More cases of paroxetine withdrawal syndrome}

SIR: We wish to add five more cases of paroxetine withdrawal syndrome to those reported by other authors (Barr et al, 1994; Pyke, 1995).

All of our cases occurred in young women (aged 26-39 years), without concurrent organic illness, diagnosed with major depression. Paroxetine was started at a dose of $10 \mathrm{mg} /$ day in the first week and increased to $20 \mathrm{mg}$ for the rest of the treatment period (12-14 months). The drug was well tolerated and laboratory tests were always normal throughout the period. A benzodiazepine was used during the first 2-3 months as an adjunct to manage anxiety but paroxetine was, thereafter, the only maintenance treatment.

In three cases paroxetine was discontinued by alternating $20 \mathrm{mg}$ one day and $10 \mathrm{mg}$ the other day during a week. After that, $10 \mathrm{mg} /$ day was maintained for 15 days, then patients were prescribed $10 \mathrm{mg}$ every other day for one more week, before stopping medication. In two patients the tapering was done directly from 20 to $10 \mathrm{mg}$ and after 2 weeks on this dose they stopped the medication.

All patients complained of vertigo, lightheadedness or gait instability during withdrawal. Three patients referred to the symptoms in their next planned out-patient consultation, but two demanded urgent treatment and were prescribed lorazepam $1 \mathrm{mg} /$ day for one week. In all five cases, the symptoms persisted for approximately 7 days.

Very similar withdrawal syndromes have been described with other serotonin selective reuptake inhibitors including fluvoxamine, fluoxetine and sertraline, and muscarinic and serotonergic factors have been implicated in the production of these symptoms but what is striking from a clinical point of view is the fact that a conservative tapering regime was unable to prevent symptoms appearing. As a result of this experience we are now applying a dosage reduction of $5 \mathrm{mg}$ per week in an attempt to avoid this withdrawal syndrome.

Barr, L. C., Goodman, W. K. \& Price, L. H. (1994) Physical symptoms associated with paroxetine discontinuation (letter) American Journal of Psychiatry, 151, 289.
BerLIN, C. S. (1996) Fluoxetine withdrawal symptoms (letter). Journal of Clinical Psychiatry, 57, 93-94.

Pyke, R. E. (1995) Paroxetine withdrawal syndrome (letter). American Journal of Psychiatry, 152, 149.

L. Pacheco

P. Malo

E. Aragues

C.S.M. Echaniz

M. ETXEBeste

Servicio Vasco de Salud

Bilbao, Spain

\section{Yohimbine and sinusitis}

SIR: There is clinical evidence that yohimbine has an effect in restoring erectile capacity in men with erectile dysfunction (ED) but may be accompanied by side-effects.

\section{Case report}

A 59-year-old man described a 3 year history of erectile dysfunction. After discussing treatment options he chose oral medication. A trial of yohimbine $5.4 \mathrm{mg}$ tid. was initiated. Three days after starting medication he developed pain and discomfort above both eyes which he described as like 'a thick head cold'. The area was tender to touch but there were no other symptoms to suggest sinus problems, influenza or an anxiety state. There was no change in his mental state. He stopped medication and symptoms resolved within 24 hours. A week later he re-exposed himself to the tablets and symptoms returned after three days, and again resolved within 24 hours of stopping. During each treatment period, no success was noted with sexual function. The patient refused a third trial of yohimbine with phenylephrine cover.

Yohimbine is an alpha-2-adrenergic antagonist. Sinus congestion is treated with a decongestant agent like phenylephrine, a direct acting alpha agonist which causes peripheral vasoconstriction. It is possible that the described symptoms are a consequence of alpha-2-adrenergic antagonism affecting the sinus mucosa. This may explain the delay in onset of symptoms similar to the latent clinical response of the drug. Side-effects would be expected to occur rapidly given the short plasma half life of 35 minutes (Owen et al, 1987). There are no reports in the literature associating yohimbine and sinusitis, 